\title{
ANÁLISE DO COMPORTAMENTO DA FLUIDODINÂMICA DO LEITO DE JORRO CÔNICO COM MISTURAS DE AREIA E CASCA DE MACADÂMIA
}

\author{
B. P. LIBARDI ${ }^{1}$, K. M. BARCELOS ${ }^{1}$, T. P. XAVIER ${ }^{1}$, M. S. BACELOS ${ }^{1}$, \\ M. A. S. BARROZO ${ }^{2}$, T. S. LIRA ${ }^{1 *}$ \\ ${ }^{1}$ Universidade Federal do Espírito Santo, Departamento de Engenharias e Tecnologia, \\ ${ }^{2}$ Universidade Federal de Uberlândia, Faculdade de Engenharia Química \\ *e-mail: taisa.lira@ufes.br
}

\begin{abstract}
RESUMO
A grande preocupação a respeito do consumo de energia e da poluição causada pelos resíduos tem incentivando, cada vez mais, pesquisas relacionadas ao desenvolvimento de energia renovável. Neste contexto, a biomassa tem se destacado como uma importante fonte alternativa de geração renovável de energia e na derivação de produtos químicos. Dentre as tecnologias de aproveitamento energético de biomassas, a técnica de pirólise vem recebendo atenção especial. Este processo, porém, necessita de um equipamento que proporcione um eficiente contato entre o fluido e a partícula. Sob esta perspectiva, o leito de jorro vem sendo estudado, e, sobretudo considerado uma boa opção para tal processo. Desta forma, para contribuir para a utilização do leito de jorro cônico como um reator de pirólise, o trabalho estudou a fluidodinâmica do processo operando com misturas de areia e casca de macadâmia, com diferentes níveis de fração mássica e de altura das partículas no leito estático. A análise das curvas características da queda de pressão em função da velocidade do ar permitiu identificar a estabilidade do regime em todas as condições estudadas. Os índices de segregação revelam que a condição de $25 \%$ em massa de biomassa e altura de $12 \mathrm{~cm}$ foi ideal para não haver segregação. Os resultados obtidos pelo planejamento fatorial $3^{2}$ comprovaram a influência da altura e da composição mássica da mistura sobre índice de segregação na base do leito.
\end{abstract}

\section{INTRODUÇÃO}

O Brasil ocupa a sexta colocação no ranking mundial de produtores de macadâmia e o estado do Espírito Santo é o segundo maior produtor no cenário nacional, sendo a região norte do estado a responsável por grande parte da produção (FRANÇA, 2007).

$\mathrm{O}$ fruto da macadâmia é composto por três partes: amêndoa (embrião), casca (endocarpo) e carpelo (exocarpo e mesocarpo), conforme mostrado na Figura 1. $\mathrm{O}$ beneficiamento da macadâmia gera, além da amêndoa, principal produto comercial, 70$77 \%$ de resíduos (casca e carpelo) (PIMENTEL, 2007).

Um dos principais métodos utilizados na conversão termoquímica de biomassa é a pirólise (ou suas variações: liquefação, gaseificação e carbonização). É um processo de decomposição termoquímica que ocorre na ausência total de oxigênio ou uma quantidade significativamente menor que a necessária para uma combustão completa. O processo permite ser direcionado para a produção de um dos subprodutos: gases $\left(\mathrm{CO}_{2}, \mathrm{H}_{2}, \mathrm{CH}_{4}\right.$, 
CO), líquidos (extrato ácido e bio-óleo) ou sólidos (carvão), dependendo das condições operacionais e do reator a ser utilizado.

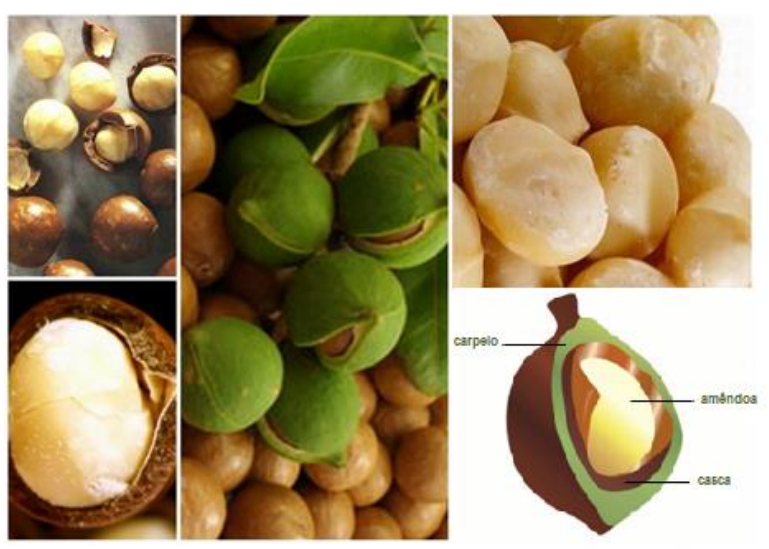

Figura 1- Fruto da macadâmia.

O leito de jorro cônico é uma alternativa viável de reator para a pirólise por apresentar um bom contato gás-sólido, altas taxas de transferência de calor e massa, bem como de recirculação de partículas, favorecendo os processos físico-químicos que ocorrem durante o processo.

Alguns trabalhos comprovaram a eficiência do leito de jorro cônico para a conversão térmica, como por exemplo: pirólise de carvão em leito de jorro (TEO; WATKSINSON, 1986); pirólise e gaseificação de lodo de esgoto (PATERSON et al., 2004); gaseificação de casca de coco (HOQUE; BHATTACHARYA, 2001); pirólise de bagaço da cana de açúcar (SANTOS, 2011) e pirólise de resíduos de pneus em um reator leito de jorro cônico sob condições de vácuo (OLAZAR et al., 2010).

Existem poucos estudos publicados sobre a pirólise de casca de macadâmia (PING et al., 2006; KARTALA et al., 2011 e $\mathrm{KO}$ et al., 2014). Um grupo de pesquisadores da Universidade Federal do Espírito Santo, Campus São Mateus, estuda os fundamentos da pirólise dessa biomassa. Entre os trabalhos estão a estimação de parâmetros cinéticos das duas etapas do processo de pirólise da casca de macadâmia, secagem e devolatilização
(XAVIER et al, 2014; BASILIO et al, 2013 e ALMEIDA et al, 2014).

Uma etapa importante na avaliação do uso do leito de jorro cônico na pirólise de casca de macadâmia é o conhecimento do comportamento fluidodinâmico das partículas. No leito de jorro, um material inerte, geralmente areia, é adicionado a fim de conferir estabilidade fluidodinâmica. Desta forma, como o intuito de contribuir para a aplicação do leito de jorro cônico como reator de pirólise de casca de macadâmia, o presente trabalho teve como objetivo estudar o comportamento fluidodinâmico do leito, avaliando o efeito da altura do leito estático e da mistura casca de macadâmia e areia em diferentes proporções na segregação e fluidodinâmica das partículas.

\section{METODOLOGIA}

A unidade experimental apresentada na Figura 2 é composta por uma coluna cônica de aço com ângulo de $45^{\circ}$, uma coluna cilíndrica de vidro, um transdutor de pressão da marca Dwiyer, modelo 616C-4, operando numa faixa de 0-20 IN WC localizado na saída de ar, um sistema de aquecimento com controle de temperatura PID e um soprador centrífugo de 2HP IBRAM com taxa de fluxo de ar de 4,5m3/min. As informações sobre a queda de pressão no leito, a vazão e a temperatura de ar injetado são obtidas no painel de controle do equipamento ou por meio de um sistema de aquisição de dados.

A Figura 3 apresenta uma representação esquemática do leito utilizado nos experimentos com as guilhotinas acopladas. A segregação axial foi determinada com a utilização de guilhotinas que separam a massa contida no leito em cinco regiões (1 a $5)$, sendo a região 1 referente ao volume da região superior do leito e a região 5 referente a base do leito.

Para a obtenção dos dados fluidodinâmicos no leito de jorro cônico 
foram utilizadas amostras de casca da macadâmia e a areia, como material inerte. As partículas de casca de macadâmia apresentam um diâmetro de $1,85 \mathrm{~mm}$ e massa específica $1190 \mathrm{~kg} / \mathrm{m}^{3}$, enquanto as partículas de areia apresentam um diâmetro de $2,58 \mathrm{~mm}$ e massa específica de $2340 \mathrm{~kg} / \mathrm{m}^{3}$.

A metodologia do planejamento de experimentos fatorial $3^{2}$ foi aplicada para analisar os efeitos da altura de leito estático $\left(\mathrm{H}_{0}\right)$ e da fração mássica de casca de macadâmia $\left(\mathrm{Xb}_{0}\right)$ sobre índice de segregação axial das partículas de areia $\left(\mathrm{I}_{\mathrm{M}}\right)$. Na matriz de planejamento, os níveis da fração mássica de biomassa foram: 0,$25 ; 0,50$ e 0,75 e para a altura de leito estático adotou-se os níveis: 12; 14 e $16 \mathrm{~cm}$.

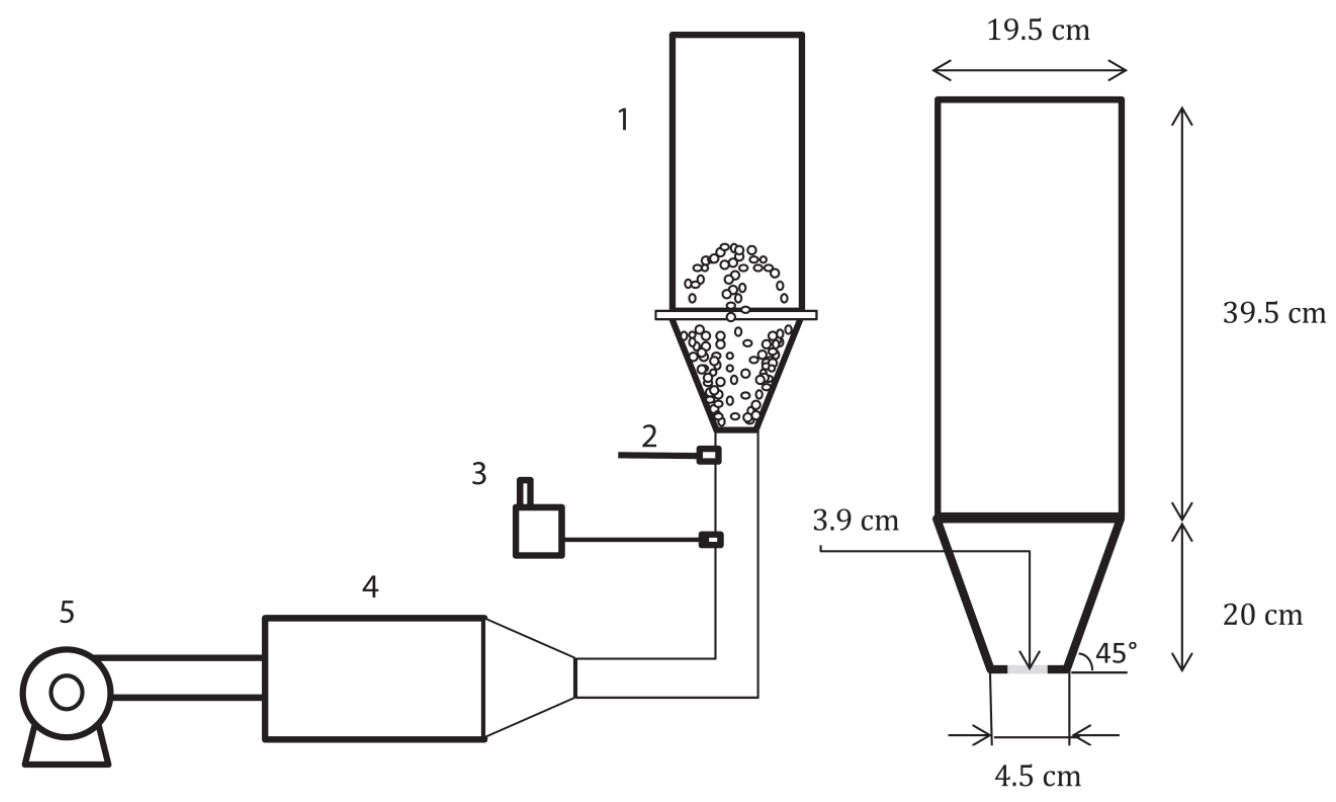

Figura 2 - Unidade experimental do leito de jorro (1) leito de jorro cônico, (2) termopar, (3) transdutor de pressão, (4) sistema de aquecimento de ar com controlador de temperatura do tipo PID, (5) soprador.

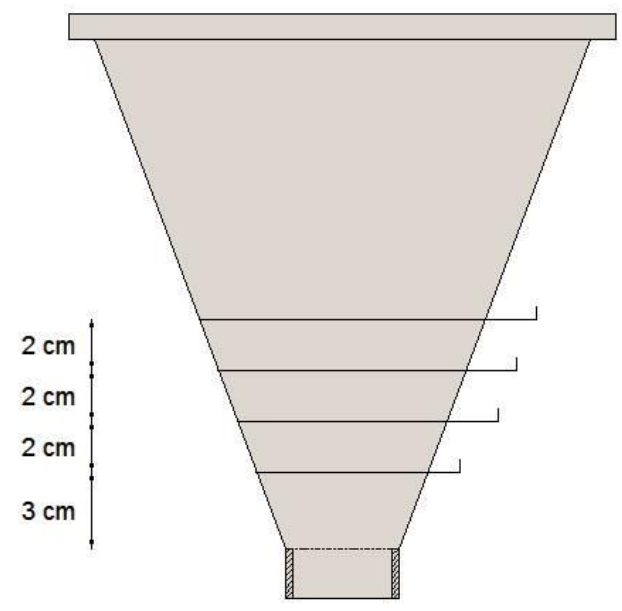

Figura 3 - Esquema da base cônica do leito com as guilhotinas.
Para a realização do experimento, as massas das partículas (biomassa e areia) foram adicionadas aleatoriamente na base cônica do leito até atingir a altura de leito estático desejada. Em seguida, a corrente de ar foi injetada à base do leito de forma a aumentar a sua intensidade gradativamente até um valor $20 \%$ maior que a vazão mínima de jorro. Posteriormente, a vazão de ar foi reduzida até a intensidade mínima alcançada pelo equipamento.

As misturas de partículas contidas em cada uma das regiões delimitadas pelas guilhotinas foram separadas por peneiramento. A Equação 1 apresenta o índice de segregação das partículas de areia na 
região $R\left(I_{M-R}\right)$, descrito pela relação entre a composição mássica na região de interesse $\left(\mathrm{Xb}_{\mathrm{R}}\right)$ e na composição inicial $\left(\mathrm{Xb}_{0}\right)$.

$I_{M-R}=\frac{X b_{R}}{X b_{0}}$

A temperatura da corrente de ar foi mantida próxima a $30^{\circ} \mathrm{C}$ e os experimentos foram realizados em triplicata, mantendo as mesmas condições de compactação do leito.

\section{RESULTADOS E DISCUSSÃO}

A Figura 4 apresenta as curvas de queda de pressão $(\Delta \mathrm{P})$ em função de uma velocidade adimensional (velocidade/ velocidade mínima de jorro, v/vmj) para os três níveis da fração mássica de biomassa $\left(\mathrm{Xb}_{0}\right)$ : a) 0,25 ; c) 0,50 ; e) 0,75 e uma altura de leito fixo $\left(\mathrm{H}_{0}\right)$ igual a $14 \mathrm{~cm}$, além dos respectivos desvios da queda de pressão.

Analisando de forma geral as curvas características, observa-se uma região em que o ar flui entre as partículas e o sistema se comporta como um leito fixo, com a característica linear do aumento da queda de pressão. Posteriormente inicia-se a expansão do leito, o que caracteriza uma diminuição na queda de pressão, uma vez que a corrente de ar começa a vencer a força resistiva que as partículas exerciam contra o seu movimento.

Em seguida nota-se a agitação das partículas, o que caracteriza o surgimento de um canal interno que aumenta gradativamente até culminar na formação da região de jorro. O aumento da vazão de ar depois da formação da fonte acarreta no aumento da altura do jorro. Com a redução da vazão de ar, nota-se o ponto de menor queda de pressão, que corresponde à vazão mínima de jorro. A partir desse ponto, ocorre novamente um aumento e posteriormente uma diminuição na queda de pressão, caracterizando o fim da presença da fonte.
A viabilidade do leito de jorro cônico como um reator de pirólise está diretamente relacionada a um baixo índice de segregação axial e radial entre as partículas. De acordo com Bacelos et al. (2007), a inércia de uma partícula influencia no seu deslocamento na direção radial do leito, de forma que as partículas mais densas atingem uma menor altura na fonte e se depositam sobre uma região mais próxima a fonte. Devido às características das partículas utilizadas, não foi observada segregação radial no decorrer dos experimentos.

A Figura 5 apresenta uma análise comparativa entre os índices de segregação axial das partículas $\left(\mathrm{I}_{\mathrm{M}-\mathrm{R}}\right)$, relacionados a diferentes condições de $\mathrm{Xb}_{0}$ e $\mathrm{H}_{0}$. A condição ideal de segregação pode ser expressa quando o $\mathrm{I}_{\mathrm{M}} \approx 1$, assim pode-se observar que o índice se mantém próximo ao ideal na condição $\mathrm{Xb}_{0}=0,25$. A condição $\mathrm{Xb}_{0}=0,50$ apresenta valores aceitáveis para o índice nas quatro primeiras regiões, apresentando uma discordância da idealidade apenas na região 5 , enquanto a condição $\mathrm{Xb}_{0}=0,75$ não apresenta um perfil ideal de segregação.

A Tabela 1 apresenta a matriz do planejamento fatorial $3^{2}$, utilizado nesse trabalho. As variáveis $\mathrm{X}_{1}$ e $\mathrm{X}_{2}$ representam de forma codificada os diferentes níveis de fração mássica de casca de macadâmia $\left(\mathrm{Xb}_{0}\right)$ e altura do leito fixo $\left(\mathrm{H}_{0}\right)$, respectivamente. Os valores do índice de segregação da areia na região 5 ( $\left.\mathrm{I}_{\mathrm{M}-5}\right)$, correspondente a parte inferior do leito, onde houve maior segregação, foi adotada com variável de resposta.

As Equações 2 e 3 apresentam a codificação das variáveis fração mássica de biomassa e altura do leito estático, respectivamente.

$X_{1}=\frac{X b_{0}-0,50}{0,25}$ 


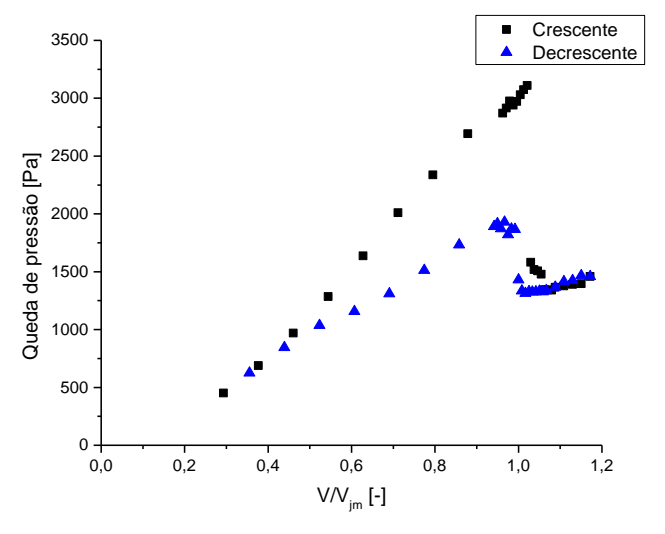

(a)

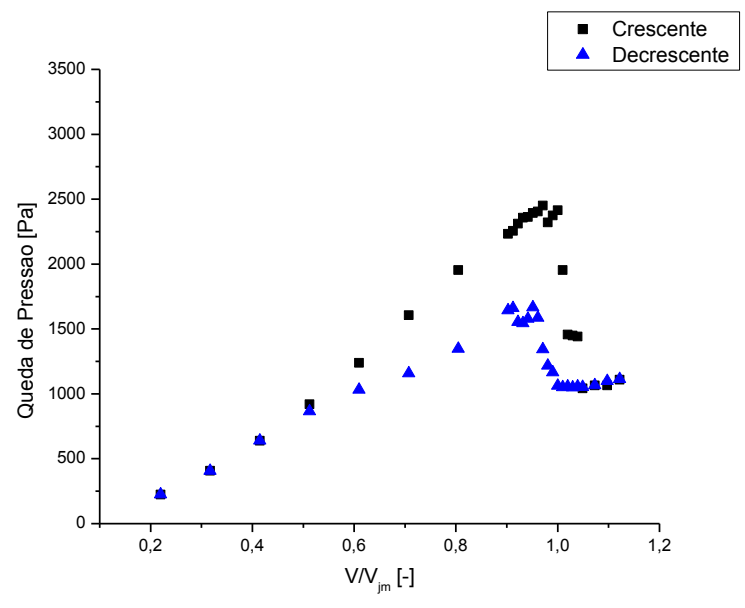

(c)

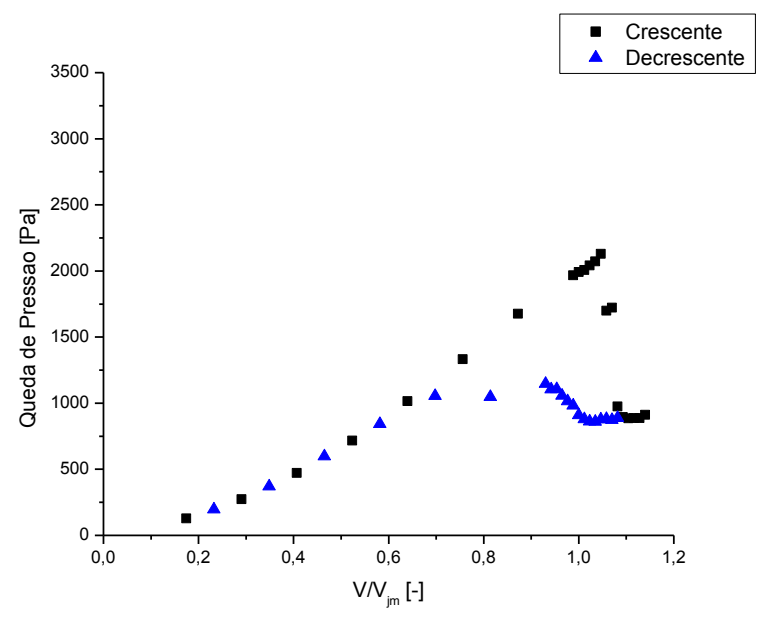

(e)

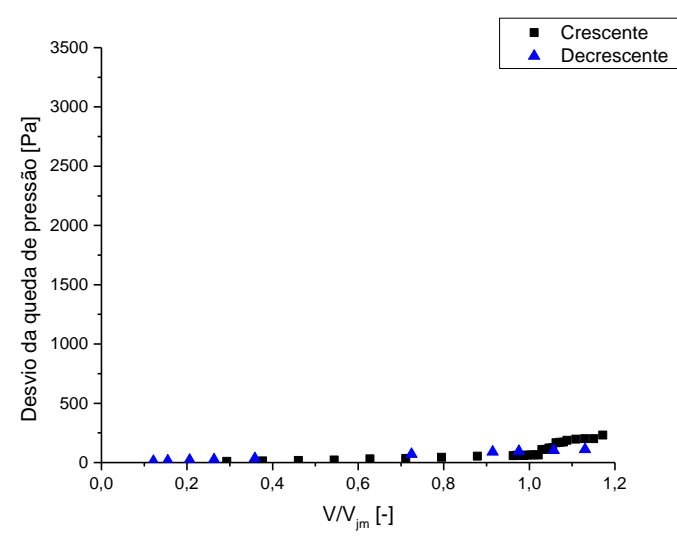

(b)

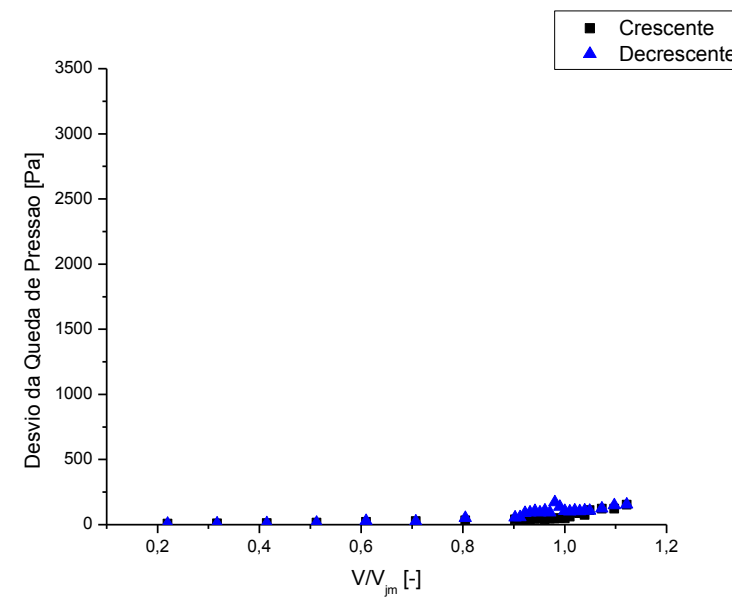

(d)

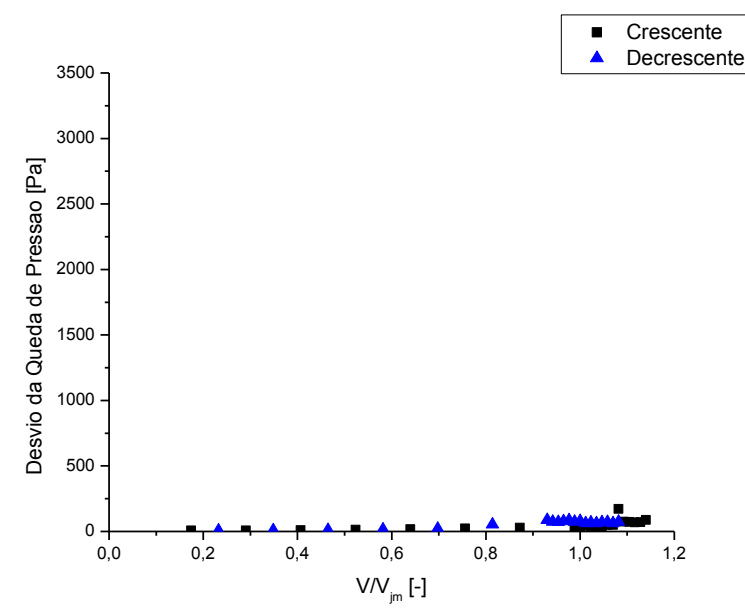

(f)

Figura 4 - Curvas características para os três níveis da fração mássica de biomassa $\left(\mathrm{Xb}_{0}\right)$ : a) 0,$\left.\left.25 ; \mathrm{c}\right) 0,50 ; \mathrm{e}\right)$ 0,75 e uma altura de leito fixo $\left(\mathrm{H}_{0}\right)$ igual a $14 \mathrm{~cm}$, além dos respectivos desvios da queda de pressão $(\mathrm{b}, \mathrm{d}$ e f). 


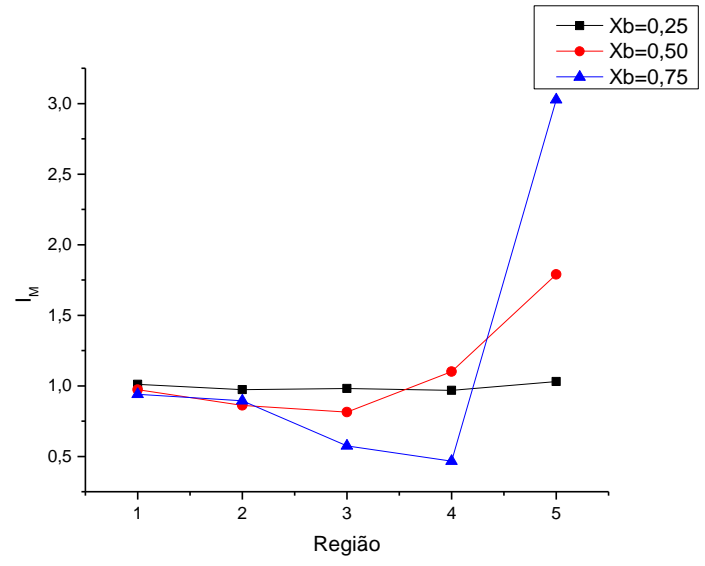

(a)

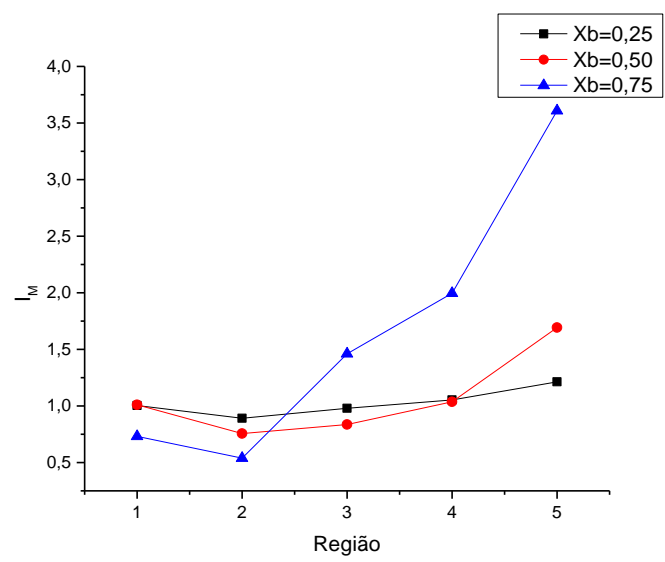

(b)

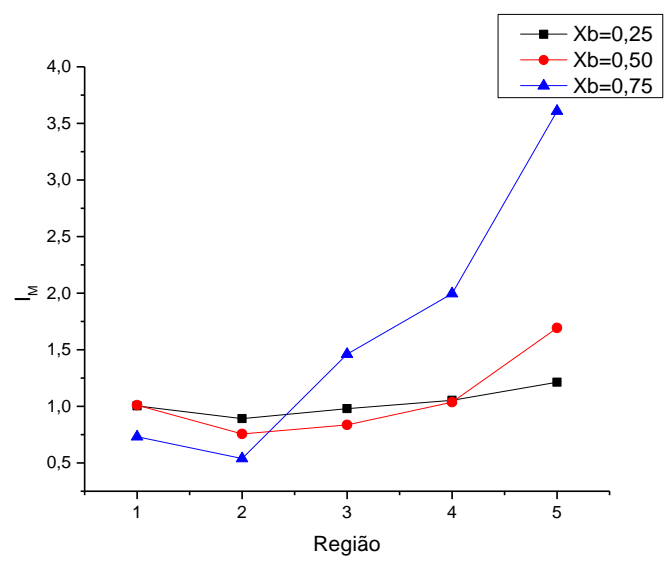

(c)

Figura 5 - Índice de segregação nas regiões do leito de jorro para as alturas de $\mathrm{H}=12 \mathrm{~cm}$ (a), $\mathrm{H}=14 \mathrm{~cm}$ (b) e $\mathrm{H}=16 \mathrm{~cm}$ (c).
$X_{2}=\frac{H_{0}-14}{2}$

Tabela 1 - Planejamento fatorial 32: segregação na base do leito de jorro.

\begin{tabular}{ccccc}
\hline $\mathrm{Xb}_{0}$ & $\mathrm{H}_{0}[\mathrm{~cm}]$ & $\mathrm{X}_{1}$ & $\mathrm{X}_{2}$ & $\mathrm{I}_{\mathrm{M}-5}$ \\
\hline 0,25 & 12 & -1 & -1 & 1,0298 \\
0,50 & 12 & 0 & -1 & 1,7890 \\
0,75 & 12 & 1 & -1 & 3,0263 \\
0,25 & 14 & -1 & 0 & 1,2130 \\
0,50 & 14 & 0 & 0 & 1,6920 \\
0,75 & 14 & 1 & 0 & 3,6084 \\
0,25 & 16 & -1 & 1 & 1,233 \\
0,50 & 16 & 0 & 1 & 1,8592 \\
0,75 & 16 & 1 & 1 & 3,6589 \\
\hline
\end{tabular}

A Tabela 2 apresenta os efeitos das variáveis $\mathrm{Xb}_{0}$ e $\mathrm{H}_{0}$ sobre $\mathrm{o}$ índice de segregação na região 5 do leito (fundo). Com um nível de significância de $10 \%$, foram considerados apenas os termos que influenciaram significativamente a variável resposta.

Observa-se que os efeitos lineares das variáveis isoladas $\left(\mathrm{X}_{\mathrm{b} 0} \quad \mathrm{e} \quad \mathrm{H}_{0}\right)$ foram significativos, além do efeito quadrático de $\mathrm{X}_{\mathrm{b} 0}$. O índice de segregação aumenta diretamente com o aumento da altura do leito estático e o aumento da fração mássica da casca de macadâmia. Desta forma, os maiores valores das variáveis respostas são observados combinando maiores valores de altura de leito estático e maior fração mássica da casca de macadâmia. Além disso, nota-se que a variável $\mathrm{X}_{\mathrm{b} 0}$ influencia o índice de segregação sete vezes mais que a variável $\mathrm{H}_{0}$.

Tabela 2 - Efeitos das variáveis $\mathrm{Xb}_{0}$ e $\mathrm{H}_{0}$ sobre o índice de segregação na base do leito $\left(\mathrm{R}^{2}=0,982\right)$.

\begin{tabular}{cccc}
\hline Fator & Efeito & Desvio Padrão & p-valor \\
\hline Média & 2,123 & 0,0576 & $<0,001$ \\
$\mathrm{X}_{1}$ (linear) & 2,273 & 0,1412 & $<0,001$ \\
$\mathrm{X}_{1}$ (quadrático) & $-0,515$ & 0,1223 & 0,008 \\
$\mathrm{X}_{2}$ (linear) & 0,302 & 0,1412 & 0,085 \\
\hline
\end{tabular}


A Equação 4 expressa o índice de segregação na base do leito (região 5), com $\mathrm{R}^{2}=0,983$, sendo os resíduos aleatórios e normalmente distribuídos.

$I_{M}=2,123-0,257 X_{1}^{2}+1,136 X_{1}+0,151 X_{2}$

em que $X_{1}$ e $X_{2}$ são, respectivamente, a fração mássica da casca de macadâmia e a altura de leito estático codificados.

Obteve-se também a superfície de resposta para o índice de segregação na base do leito (região 5) em função a fração mássica da casca de macadâmia e a altura de leito estático (Figura 6). Como pode ser observada, a condição de operação ótima do experimento, ou seja, aquela em que a segregação das partículas é mínima, foi para o menor valor de fração mássica da casca de macadâmia (25\%) e menor a altura de leito estático $(12 \mathrm{~cm})$.

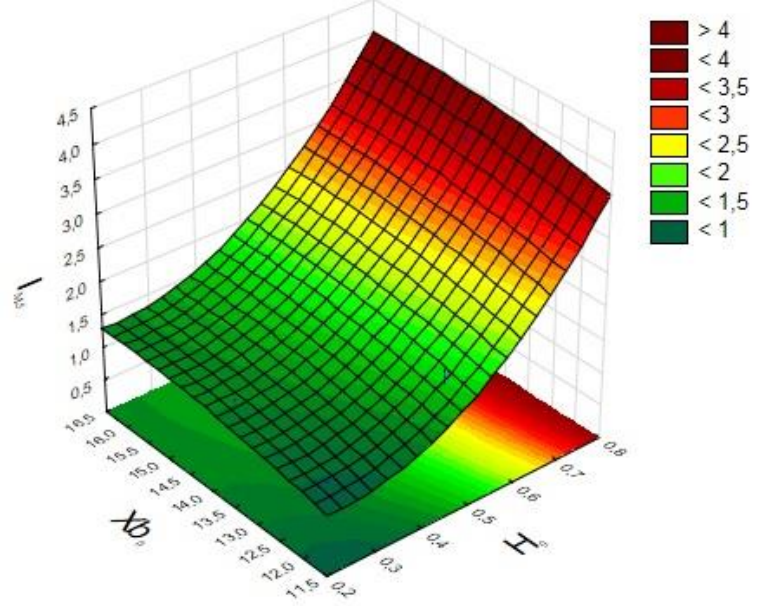

Figura 6 - Superfície de resposta para o índice de segregação $\mathrm{I}_{\mathrm{M}-5}$ em função de $\mathrm{H}_{0}$ e $\mathrm{X}_{\mathrm{b} 0}$.

\section{CONCLUSÕES}

O regime de jorro da mistura de partículas de areia e casca de macadâmia apresentou-se estável em todas as condições de composição mássica e altura do leito estático utilizadas no estudo.
As curvas características de queda de pressão em função da velocidade de ar apresentaram perfis condizentes com os apontados na literatura e o desvio da queda de pressão para as respectivas curvas exibem baixas flutuações, garantindo boa estabilidade do leito de jorro.

A análise de segregação das partículas mostra que a condição $\mathrm{Xb}_{0}=0,25$ apresenta os índices de segregação mais próximos aos da idealidade em todas as regiões do leito, enquanto a condição $\mathrm{Xb}_{0}=0,50$ não se adequa a idealidade somente na região 5 , referente a base do leito. A condição $\mathrm{Xb}_{0}=0,75$ se mostra inviável, visto que apresenta níveis elevados de segregação em todas as regiões estudadas.

$\mathrm{O}$ planejamento $3^{2}$ revelou que $\mathrm{O}$ índice de segregação das partículas na região 5 sofre não só a influência linear da altura do leito, como também a influência linear e quadrática do termo referente à composição mássica da mistura de partículas. $\mathrm{O}$ aumento do índice de segregação está diretamente relacionado com o aumento da fração mássica da biomassa e com o aumento da altura do leito estático. $\mathrm{O}$ estudo revelou que a condição ideal para a não ocorrência do efeito da segregação é $\mathrm{Xb}_{0}=0,25$ e $\mathrm{H}=12 \mathrm{~cm}$.

Por apresentar características fluidodinâmicas viáveis, o estudo aponta o leito de jorro como um reator com potencial aplicação para a pirólise de cascas de macadâmia.

\section{NOMENCLATURA}

$\mathrm{H}_{0}-$ Altura de leito estático [cm]

$\mathrm{Xb}_{0}$ - Fração mássica de biomassa

$\mathrm{Xb}_{\mathrm{R}}$-Fração mássica de biomassa na região $\mathrm{R}$ $\mathrm{I}_{\mathrm{M}}$ - Índice de segregação axial das partículas

$\mathrm{I}_{\mathrm{M}-\mathrm{R}}$ - Índice de segregação axial das partículas na região $\mathrm{R}$

$\Delta \mathrm{P}$ - Queda de pressão [Pa]

$\mathrm{V}$ - velocidade do ar $[\mathrm{m} / \mathrm{s}]$ 
$\mathrm{V}_{\mathrm{mj}}$ - velocidade do ar na condição de mínimo jorro $[\mathrm{m} / \mathrm{s}]$

$\mathrm{X}_{1}$ - Fração mássica codificada

$\mathrm{X}_{2}-$ Altura do leito estático codificada

\section{REFERÊNCIAS}

ALMEIDA， P. S.; BACELOS, M. S. ; XAVIER, T. P.; BARROZO, M. A. S.; LIRA, T. S. Estimação de parâmetros cinéticos da secagem da casca da macadâmia em camada fina. Anais do X Congresso Brasileiro de Engenharia Química em Iniciação Científica, 2014.

BACELOS, M. S.; PASSOS, M. L.; FREIRE, J. T. Effect of interparticle forces on the conical spouted bed behavior of wet particles with size distribution. Powder Technology, v. 174, n.3, p. 114-126, 2007.

BARCELOS, K. M.; XAVIER, T. P.; BACELOS, M. S.; BARROZO, M. A. S. ; LIRA, T. S. Discriminação de equações para isotermas da umidade de equilíbrio da casca de macadâmia. Anais do X Congresso Brasileiro de Engenharia Química em Iniciação Científica, 2014.

BASILIO, A.; BACELOS, M. S.; XAVIER, T. P.; BARROZO, M. A. S.; LIRA, T. S. Determinação da energia de ativação da pirólise do carpelo de macadâmia utilizando modelos isoconversionais Anais do XXXVI Congresso Brasileiro de Sistemas Particulados, 2013.

FRANÇA, B. C. Macadâmia - cultivo e produtos derivados. REDETEC Rede de Tecnologia do Rio de Janeiro. Rio de Janeiro, setembro 2007. Disponível em: $<$ http://www.respostatecnica.org.br/dossietecnico/downloadsDT/MjAy>. Acesso em: 10/06/2015.
HOQUE, M. M.; BHATTACHARYA, S. C. Fuel characteristics of gasified coconut shell in a fluidized and a spouted bed reactor. Energy, v. 26, p. 101 - 110, 2001.

KARTAL, S. N.; TERZI, E.; KOSE, C.; HOFMEYR, J.; IMAMURA, Y. Efficacy of tar oil recovered during slow pyrolysis of macadamia nut shells. International Biodeterioration \& Biodegradation. V. 65, p. 369-373, 2011.

KO, K.; RAWAL, A.; SAHAJWALLA, V. Analysis of thermal degradation kinetics and carbon structure changes of co-pyrolysis between macadamia nut shell and PET using thermogravimetric analysis and 13C solid state nuclear magnetic resonance. Energy Conversion and Management, v. 86, p. 154-164, 2014.

PING, N.; YUE-HONG, Y.; JIN-HUI, P.; SHI-MIN, Z.; LI-BO, Z.; YU-BAO, C. Study on Pyrolysis Characteristics of Macadamia Shell during Preparation of Activated Carbon. Chemistry and Industry of Forest Products, v. 26, p.61-64, 2006.

OLAZAR, M.; LOPEZ, G.; AGUADO, R.; ELORDI, G.; AMUTIO, M.; ARTETXE, M.; BILBAO, J. Vacuum pyrolysis of waste tires by continuously feeding into a conical spouted bed reactor. Industrial \& Engineering Chemistry Research, v. 49, p. 8990-8997, 2010.

PATERSON, N.; ZHUO Y.; REED G. P.; DUGWELL D. R.; KANDIYOTI R. Pyrolysis and gasification of sewage slugde in a spouted-bed reactor. Water and Environment Journal, v. 18, p. 90-95, 2004.

PIMENTEL, L. D. A cultura da macadâmia. Revista Brasileira de Fruticultura, v. 29, p. 414-716, 2007. 
SANTOS, K. G. Aspectos fundamentais da pirólise de biomassa em leito de jorro: fluidodinâmica e cinética do processo, 2011. Tese (Doutorado em Engenharia Química) Programa de Pós-Graduação em Engenharia Química, Universidade Federal de Uberlândia, Uberlândia, 2011.

TEO, K. C.; WATKINSON, A. P. Rapid pyrolysis of Canadian coals in a miniature spouted bed reactor. Fuel, v. 65, p. 949-959, 1986.

XAVIER, T. P.; LOSS, F. D.; LIRA, T. S.; BARROZO, M. A. S. Estudo da cinética da írólise da casca de macadamia: determinação da energia de ativação global usando modelos isoconversionais. XIX Jornada em Engenharia Química, Universidade Federal de Uberlândia, 2014.

\section{AGRADECIMENTOS}

Os autores agradecem ao CNPQ e a FAPES pelo apoio financeiro na realização desta pesquisa. 